\title{
Recent Advancement of Cooling and Heat Transfer of Diesel Engine
}

\author{
Chunhao Yang ${ }^{1}$, Ruilin Liu $^{2, *}$, Yufei Jiao ${ }^{2}$, Zhongjie Zhang ${ }^{2}$ and Nanlong Xia ${ }^{2}$ \\ ${ }^{1}$ College of Power Engineering, Naval University of Engineering, Wuhan 430033, China \\ ${ }^{2}$ Department of Military Vehicle, Army Military Transportation University, Tianjin 300161, China \\ ${ }^{*}$ Corresponding author
}

\begin{abstract}
The study of diesel cooling and heat transfer can improve thermal efficiency and reduce exhaust emissions. The research on the heat transfer characteristics of diesel engine block, the influence of the cooling medium control parameters on the heat transfer characteristics of the cooling system and environmental boundary conditions on the heat transfer characteristics of the diesel engine are elaborated, which as the breakthrough point of the research on the cooling heat transfer of diesel engine. The further development direction is discussed. It is pointed out that the research on the content of the best nanoparticles in the nanofluids, the durability test of the low heat rejection (LHR) diesel engine and the intelligent integrated control of the cooling system of the diesel engine at plateau are the key points of the research on the cooling and heat transfer of the diesel engine in the future.
\end{abstract}

Keywords-heat transfer characteristics; diesel engine; cooling medium control parameters; environmental boundary conditions

\section{INTRODUCTION}

In the field of power machinery, diesel engine has a very obvious advantage. Its high thermal efficiency, wide speed range and low fuel consumption make the diesel engine widely used in the world. Under various operating conditions, diesel engines have become an irreplaceable source of power to help people accomplish various social tasks.

The work of diesel engine is essentially a process of energy conversion and heat transfer. With the improvement of the diesel engine, the increase of the power density and the stricter emission regulations, the demand for the thermal efficiency of the diesel engine is higher than that of the diesel engine.

The thermal management of diesel engine is aimed at optimizing the thermal balance performance by controlling the cooling system, which based on the heat transfer characteristics of diesel engine. It can improve the thermal efficiency of diesel engine, improve the power and economy, and control the discharge of pollutants. Therefore, to achieve the improvement of thermal management technology, the research on the cooling and heat transfer characteristics of diesel engine is the most important to achieve the improvement of thermal management technology.

From the overall working process of diesel engine, cooling and heat transfer mainly includes the following three parts [1].

- Heat transfer in the combustion chamber. After the combustion of fuel, the heat of the high temperature gas is first transmitted to the combustion chamber by convection heat transfer and radiative heat transfer.

- Heat transfer between the heated components and the coolant. The heat in the combustion chamber is transmitted from the inner surface of the chamber wall to the outer surface, and then transferred to the cooling medium by convection heat transfer.

- Heat transfer between the radiator and the cooling air. For water-cooled diesel engines, the coolant transfers heat to the cooling air through the radiator in the form of convective heat transfer.

In view of the above heat transfer process, the heat transfer characteristics of the diesel engine block, the influence of the control parameters of the cooling medium on the heat transfer characteristics of the cooling system and the influence of the environmental boundary conditions on the heat transfer characteristics of the cooling system have been studied by the experts and scholars.

\section{STUDY ON HEAT TRANSFER CHARACTERISTICS OF} DIESEL ENGINE BLOCK BASED ON HEAT TRANSFER THEORY

As shown in Figure $\mathrm{I}$ as the heat distribution map of the internal combustion engine, after the combustion of fuel in the diesel engine cylinder, $28 \%$ to $30 \%$ of the heat transfer to the cylinder wall after the heat conduction is taken away by the cooling system, $30 \%$ to $32 \%$ of the exhaust gas discharge heat, $7 \%$ to $9 \%$ of the heat for the accessories consumption and heat radiation consumption of the body. It can be seen that the study of the heat transfer characteristics of diesel engine, the optimization of the matching of the cooling system and the diesel engine, and the maximum improvement of the heat distribution are the important technical means to improve the thermal efficiency of the diesel engine, the economy and the reliability of the diesel engine [2].

According to the mechanism of heat conduction, heat convection and heat radiation heat transfer of diesel engine, in order to rationally distribute the heat of diesel engine and improve the thermal efficiency, the research institutions have studied the heat transfer characteristics of the diesel engine body, including the heat transfer characteristics in combustion chamber and the heat transfer characteristics between the heated components and coolant. 


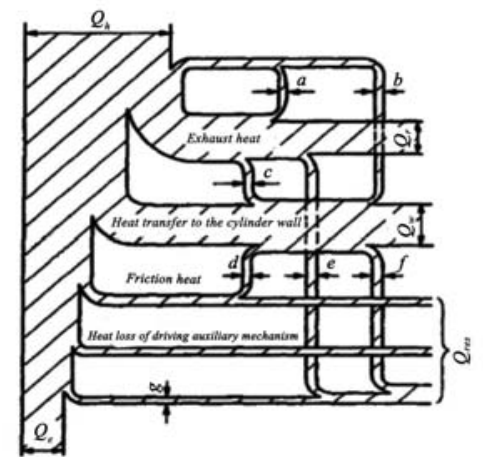

FIGURE I. HEAT DISTRIBUTION MAP OF INTERNAL COMBUSTION ENGINE

\section{A. Heat transfer characteristics in combustion chamber}

From the mechanism of heat transfer, there are three basic modes of heat transfer, namely, heat conduction, thermal convection and thermal radiation. In the process of cooling and heat transfer in diesel engine, most of the heat transfer is the process of heat transfer between fluid and the surface of an object when the fluid flows through the surface of an object. It is called convective heat transfer. It is not a basic heat transfer mode, but a heat transfer process that relies on the two modes of heat conduction and thermal convection, as shown in Table I as a heat transfer analysis for different parts of a diesel engine [1,3-5].

TABLE I. HEAT TRANSFER ANALYSIS OF DIFFERENT PARTS OF DIESEL ENGINE

\begin{tabular}{|c|c|c|c|c|c|}
\hline \multicolumn{2}{|c|}{$\begin{array}{c}\text { Heat Transfer } \\
\text { Medium }\end{array}$} & $\begin{array}{c}\text { Heat } \\
\text { Transfer } \\
\text { Mode }\end{array}$ & \multicolumn{2}{|c|}{$\begin{array}{l}\text { Heat Transfer } \\
\text { Medium }\end{array}$} & $\begin{array}{c}\text { Heat } \\
\text { Transfer } \\
\text { Mode }\end{array}$ \\
\hline \multirow{4}{*}{ Gas } & $\begin{array}{l}\text { Cylinder } \\
\text { head }\end{array}$ & \multirow{4}{*}{$\begin{array}{l}\text { Convective } \\
\text { heat } \\
\text { transfer, } \\
\text { Radiative } \\
\text { heat } \\
\text { transfer }\end{array}$} & \multirow[t]{2}{*}{$\begin{array}{l}\text { Cylinder } \\
\text { head }\end{array}$} & $\begin{array}{l}\text { Ambient } \\
\text { air }\end{array}$ & $\begin{array}{l}\text { Convective } \\
\text { heat } \\
\text { transfer, } \\
\text { Radiative } \\
\text { heat } \\
\text { transfer }\end{array}$ \\
\hline & Piston & & & Coolant & $\begin{array}{l}\text { Convective } \\
\text { heat } \\
\text { transfer }\end{array}$ \\
\hline & $\begin{array}{l}\text { Cylinder } \\
\text { liner }\end{array}$ & & \multirow{2}{*}{ Piston } & $\begin{array}{l}\text { Engine } \\
\text { oil }\end{array}$ & $\begin{array}{l}\text { Convective } \\
\text { heat } \\
\text { transfer }\end{array}$ \\
\hline & Valve & & & $\begin{array}{l}\text { Cylinder } \\
\text { liner }\end{array}$ & $\begin{array}{l}\text { Heat } \\
\text { conduction }\end{array}$ \\
\hline \multirow{2}{*}{$\begin{array}{l}\text { Cylinder } \\
\text { liner }\end{array}$} & $\begin{array}{l}\text { Cylinder } \\
\text { head }\end{array}$ & $\begin{array}{l}\text { Heat } \\
\text { conduction }\end{array}$ & \multirow{2}{*}{ Valve } & $\begin{array}{l}\text { Cylinder } \\
\text { head }\end{array}$ & $\begin{array}{l}\text { Heat } \\
\text { conduction }\end{array}$ \\
\hline & Coolant & $\begin{array}{l}\text { Convective } \\
\text { heat } \\
\text { transfer }\end{array}$ & & $\begin{array}{l}\text { Cylinder } \\
\text { liner }\end{array}$ & $\begin{array}{l}\text { Heat } \\
\text { conduction }\end{array}$ \\
\hline
\end{tabular}

During the working process of diesel engine, the total heat of fuel burning is about $1 / 3$, which is transmitted to the wall of the combustion chamber by convective heat transfer and radiative heat transfer. This part of heat transfer will have a direct effect on the heat load of the heated parts of diesel engine during the test and operation of diesel engine. Therefore, the experts and scholars have the characteristics of the heat transfer in the combustion chamber. Firstly, the temperature field of heated parts (such as cylinder head, cylinder liner and piston) and thermal stress caused by temperature difference are analyzed. Shojaefard [6] used the empirical formula to determine the thermal boundary conditions of the cooling channel of the cylinder head, and the temperature and thermal stress field of the cylinder head are calculated by applying third kinds of boundary on the surface of the cylinder head. Memon [7] analyzed the heat transfer process of the cylinder head of a air-cooled diesel engine. The heat transfer results of the solid part were calculated by ANSYS. As the boundary condition of the fluid area, the temperature field of the cooling channel of the cylinder head was calculated, and the geometric size and the shape of the section were optimized.

Huang [8] used the ABAQUS software to carry out the thermosetting coupling analysis, simulated the temperature field of cylinder head and cylinder body, and compared the experimental results to verify the correctness of the simulated temperature field distribution, which provides the reference direction for the design and development of the diesel engine parts. Wang [9] established the finite element model of cylinder head, cylinder block, cylinder liner and other components. the temperature field and stress field of cylinder head, which after interaction of several parts, are analyzed.

With the development of alternative fuels that require high ambient temperature of the combustion chamber (such as biodiesel and alcohol) and exhaust heat recovery and utilization technology, researchers have carried out relevant research on the technology of reducing the heat transfer on the wall of the combustion chamber and increasing the temperature inside the cylinder and exhaust energy, which based on the heat conduction mechanism. [10,11] The average heat flux per unit area of the high temperature gas to the combustion chamber can be calculated [12] by

$$
\mathrm{q}=\frac{1}{\tau_{0}} \int_{0}^{\tau_{0}} h_{g}\left(t_{g}-t_{w}\right) d \tau .
$$

In the formula, $\mathrm{q}$ is the average heat flux of the cycle on the unit area of the combustion chamber wall, $\mathrm{W} / \mathrm{m}^{2} . \mathrm{h}_{\mathrm{g}}$ is the instantaneous average surface heat transfer coefficient of the gas to the chamber wall, $\mathrm{W} /\left(\mathrm{m}^{2} \cdot{ }^{\circ} \mathrm{C}\right) . \mathrm{t}_{\mathrm{g}}$ is the instantaneous temperature of the gas, ${ }^{\circ} \mathrm{C} . \mathrm{t}_{\mathrm{w}}$ is the instantaneous temperature of the combustion chamber wall, ${ }^{\circ} \mathrm{C}$. $\tau_{0}$ is a cycle period, s.

The thermal conductivity of the diesel engine can be reduced effectively by reducing the thermal conductivity of the material under the condition that the combustion temperature and the structure of the cylinder are not constant. As a result, ceramic insulation technology is generally adopted.

Ceramic insulation technology, that is, coating the ceramic layer in the combustion chamber, reduces the thermal conductivity of the material and reduces the heat conduction. In 1970s, Kamo and Bryzik [13-16] pioneered the concept of LHR diesel engine, which attracted extensive attention from experts and scholars. Then they proposed that the thermal 
insulation coating used for LHR diesel engine must have high temperature resistance, high expansion coefficient, low friction characteristics, good thermal vibration resistance, light weight, and durability. Point. Sekar and Kamo [17] developed a passenger car equipped with insulated diesel engine, which improved by $12 \%$ compared with the general diesel engine. Prasad and others use thermal insulation on the top of the piston, that is, partially stabilized zirconia (PSZ), and tests show that the loss of heat loss by the piston is as high as $19 \%$ by the piston. Taymaz [18] contrasts the heat balance performance and economy of the original and low cooling diesel engine on a 6 cylinders four stroke direct injection turbocharged diesel engine. The plasma is sprayed on the combustion chamber surface, cylinder head, valve and piston top surface by $\mathrm{CaZrO}$ and $\mathrm{MgZrO}_{3}$. The test results show the coolant zone under low, medium and high load. The heat loss decreased by $4 \%, 2 \%$ and $3 \%$ respectively, and the exhaust heat was increased by 3\%, 4\% and 8\% respectively. In 2016, Krishna [19] explored the heat transfer characteristics of the combustion chamber in the use of vegetable oils and alcohol fuels on low heat engines. The performance test of alcohols (methanol, ethanol) and leprosy oil under the different injection timing and injection pressure on the single cylinder, four stroke, water cooled LHR engine (ceramic coating) and the traditional engine at a rated power $3.68 \mathrm{~kW}$, respectively, found that the cooling load of the LHR diesel engine decreased by $12 \%$.

In 2017, the North China Engine Research Institute [20] sprayed Magnesium Oxide-partially stabilized zirconia ceramic (Mg-PSZ) and yttrium-partially stabilized zirconia ceramic (YPSZ) on the top of the piston, analyzed their effects on the temperature field and thermal stress field of a certain type of turbocharged diesel engine piston, and found that the temperature of the piston top layer compared with the uncoated piston. The temperature of the matrix increased by $50.49 \%$ and $34.81 \%$ respectively, and the corresponding temperature decreased by $28.49 \%$ and $17.34 \%$ respectively.

The amount of heat that is reduced by the LHR technology to the combustion chamber wall is basically taken away by exhaust according to the theory of diesel engine heat transfer. If this part of the heat can be reasonably utilized, the thermal efficiency of the diesel engine can be effectively improved.

\section{B. Heat transfer characteristics between the heated components and coolant}

As the power of diesel engine is continuously strengthened and improved, the components of diesel engine are in a worse working environment, and the heat load level of key components has been greatly improved. Therefore, how to use more efficient cooling mode to solve the problem of heat dissipation in diesel engine becomes very important. The heat flux density of convective heat transfer can be calculated by Newton cooling formula [21-24]

$$
\mathrm{q}=\mathrm{h}\left(\mathrm{t}_{\mathrm{w}}-\mathrm{t}_{\mathrm{f}}\right) \text {. }
$$

In the formula, $\mathrm{q}$ is the heat flux of the cooling fluid transferred to the wall of the combustion chamber, $\mathrm{W} / \mathrm{m}^{2} . \mathrm{h}$ is convective heat transfer coefficient, $\mathrm{W} /\left(\mathrm{m}^{2} \cdot{ }^{\circ} \mathrm{C}\right) . \mathrm{t}_{\mathrm{w}}$ is the
External wall temperature of combustion chamber, ${ }^{\circ} \mathrm{C}$. $\mathrm{t}_{\mathrm{f}}$ is the coolant temperature, ${ }^{\circ} \mathrm{C}$.

It is seen from the formula (2) that increasing the convection heat transfer coefficient of the coolant is an effective way to enhance the heat transfer capacity between the heating components and the coolant under the condition that the wall and the coolant temperature remain unchanged. In this regard, the current main research direction is the optimization of cooling medium materials and cooling mechanisms.

In the light of the optimization of cooling medium materials, nanofluids have attracted much attention due to their good thermal conductivity. Choi [25] points out that nanofluids have great potential as a new generation of coolant for vehicle thermal management because of the higher thermal conductivity of nanofluids. Leong [26] used nanofluids as coolant of engine. It is found that a small amount of copper nanoparticles can be added to the basic liquid glycol to enhance the heat transfer of the radiator. Zhong [27] used nanofluids, water and glycol as the cooling medium to test the heat transfer performance of the diesel engine oil cooler. It was found that the heat transfer ability of nanofluids was $4.6 \%$ and $19 \%$ higher than that of water and antifreeze at the temperature of the conventional cooling medium $\left(85{ }^{\circ} \mathrm{C}\right)$. Cui [28] simulated the heat conduction of nanofluids by molecular dynamics simulation. The coefficient is calculated and the heat conduction mechanism of nanofluids at the micro level is simulated. It is proved that the surface liquid adsorption layer and the high-speed micro motion of nanoparticles in the base liquid are the important mechanism of the nanofluids to strengthen the heat conduction. At the same time, it is found that nanofluids present a microstructural characteristic similar to solid. The microstructural characteristics of nanofluids, caused by nanoparticles, are also important mechanisms for thermal conductivity enhancement of nanofluids.

There are two different types of heat transfer in the convection heat transfer process of the coolant, one is singlephase convection heat transfer, the other is the phase change convective heat transfer (boiling heat transfer). Due to the high efficiency of phase change convective heat transfer, the heat transfer process and mechanism have attracted wide attention. The related researches [29-33] also shows that it can improve the high temperature cooling technology of diesel engine by using local bubble nucleation and strengthening wall heat transfer in the key area of cylinder head heat, which can effectively reduce the working volume of the cylinder head cooling water jacket and the flow of the coolant, improve the working temperature of the internal combustion engine and shorten the warm time required for the cold start. In order to improve the fuel economy, emission and power of the internal combustion engine. In addition, high temperature cooling also helps to reduce Gene's temperature gradient, thereby reducing the thermal stress of Gene and improving the reliability of internal combustion engine.

The template is used to format your paper and style the text. All margins, column widths, line spaces, and text fonts are prescribed; please do not alter them. You may note peculiarities. For example, the head margin in this template measures proportionately more than is customary. This measurement and 
others are deliberate, using specifications that anticipate your paper as one part of the entire proceedings, and not as an independent document. Please do not revise any of the current designations.

The influence of heat transfer material, cooling water cavity structure, cooling medium and surrounding environment on heat transfer characteristics are studied in view of the convection heat transfer in the cooling system. In 1999, Campbell [34] studied the effect of different roughness of the water chamber surface on the boiling heat transfer characteristics of diesel engine. The results show that the wall heat transfer rate of rough cast iron is higher than that of machined and polished surface when the same wall superheat is maintained. Kandilikarl [35] has studied the boiling heat transfer characteristics of the cooling medium with different ethylene glycol and water mixing ratio. It is found that the boiling heat transfer performance of the ethylene glycol is gradually decreasing with the increase of the proportion of ethylene glycol. Lee [36] used the cooling medium with 50\% glycol water solution to explore the boiling heat transfer model suitable for the engine. The experiment obtained the boiling heat transfer characteristic curve of different flow velocity, different pressure and different temperature, which provides the experimental basis for the establishment of mathematical model. In 2014, Gu [37] established a supercooled boiling heat transfer model adapted to the cooling water chamber of the cylinder head based on the VOF two-phase flow model. The evaporation and condensation process in the subcooled flow boiling was studied using CFD software and self-developed UDF function. The calculation error of the model remained within $5 \%$.

\section{INFLUENCE OF COOLING MEDIUM CONTROL PARAMETERS ON HEAT TRANSFER CHARACTERISTICS OF COOLING SYSTEM}

The traditional mechanical cooling system is driven by diesel engine crankshaft. The control parameters of cooling medium (coolant flow, coolant temperature and cooling air flow) are relatively fixed in different working environment and the same diesel engine speed. The cooling strength not can be adjusted according to the heat dissipation requirement of the diesel engine, and the "overcooling" and "overheating" are easy to appear. In the mechanical cooling system, the power consumption of the cooling water pump and the cooling fan is three times proportional to the three times of the flow and speed, so with the increase of the speed of the pump and the fan, the parasitic loss of the cooling system will increase exponentially. When full load operation, the parasitic loss of cooling system is equivalent to $10 \%$ to $20 \%$ of the output power of diesel crankshaft. Similarly, due to the coupling of cooling medium control parameters and diesel engine speed, diesel engine is prone to "hot dip" phenomenon after shutdown [38-41]. In order to reduce the parasitic loss of the cooling system and improve the thermal efficiency of the diesel engine, the experts and scholars take the development of the cooling system as a turning point to reduce the parasitic loss of the cooling system and improve the thermal efficiency of the diesel engine. The heat transfer of the cooling medium control parameters (cooling fluid flow, coolant temperature, cooling air flow) and the heat transfer of the cooling system are carried out. The study of the effect of the characteristics.

As early as in 1990, Hamamoto [42] Summed up the development of the hydraulic cooling fan and developed a new type of diesel engine cooling fan driven by hydraulic pumps and motors, which can not only obtain high winds by accurate control, but also have the best flow rate in the diesel engine. Subsequently, the IMz-FE engine used by the Toyota Auto Body Co in Lexus ES300 and Avalon cars and the 3vz-FE engine used by TOYOTA Camry sedan, which applied the electro-hydraulic proportional technology to control diesel engine cooling fan system. [43] The system can automatically adjust the speed of the fan based on cooling water temperature, ambient temperature and ventilation. Frick [44] studied the hydraulic fan driven heat exchanger of the automobile cooling system. The cooling air was provided by the hydraulic drive fan controlled by the computer. Compared with the mechanical cooling fan and the reasonable control of the cooling air, the cooling capacity of the cooling system was obviously improved.

The EMP company of the United States has shown that the use of electric three valve, electric pump and heating circuit to control the flow of the coolant reduces the preheating time of the diesel engine by 190s. On the premise of cooling the heat, more heat is converted to effective work, the fuel consumption rate is reduced by $3 \%$, and the parasitic loss when the flow of coolant is $200 \mathrm{~L} / \mathrm{min}$ is parasitized. Reducing $70 \mathrm{~W}$, the total volume demand of the coolant is reduced by $46 \%$. Hoon [45] used electronic controlled cooling water pump instead of traditional mechanical pump. It is found that it is more reasonable to control the flow of coolant under different working conditions, and the volume of radiator can be reduced by more than $27 \%$. It has great potential to improve the performance of diesel engine and fuel economy. In order to strengthen the heat transfer characteristics of the cooling system, the FAW Volkswagen designs the APF electronic control cooling system, which adopts the multi loop electric thermostat [46], which combines the coolant distribution flange and the thermostat, and controls the flow of each cooling circuit of the diesel engine, and then the base of the multi loop electric thermostat. On the basis of the technical innovation [47], the control of the small circulation of the coolant at the same time also controls the flow of multiple loops in the oil cooler, the warm air tank, the intake throttle and so on, so that the diesel engine body parts are in the best working temperature range.

In order to make the cooling system of diesel engine to adjust its cooling strength more quickly and accurately for adapting to the change of heat dissipation requirement of diesel engine caused by the change of environment and working condition, the influence of cooling medium synergistic control parameters (i.e. coolant flow, coolant temperature, cooling air flow) on heat transfer characteristics of cooling system is studied by scholars, which taking the controllable cooling system as an opportunity. Therefore, it is the most the important for the development of control strategy.

At present, the nonlinear control strategy based on Lyapunov is generally adopted to control the cooling medium parameters in the cooling system. The aim is to achieve 
accurate and accurate control of cooling strength by accurate and rapid control of cooling system under different working conditions, in order to enhance the heat transfer characteristics of the cooling system, shorten the start time and improve the thermal efficiency. Setlur [48] developed a Lyapunov based nonlinear controller. Using an electric immersion heater to simulate the combustion process of a diesel engine (as shown in Figure II), a nonlinear control algorithm is used to adjust the temperature of the coolant (the cooling system consists of electric valves, mechanical pumps and fans), and the control strategy is designed to control the constant speed of the pump and the fan. The result shows that the control strategy can reduce the temperature fluctuation during the adjustment process, and the preheating time of diesel engine is reduced by $42 \%$.

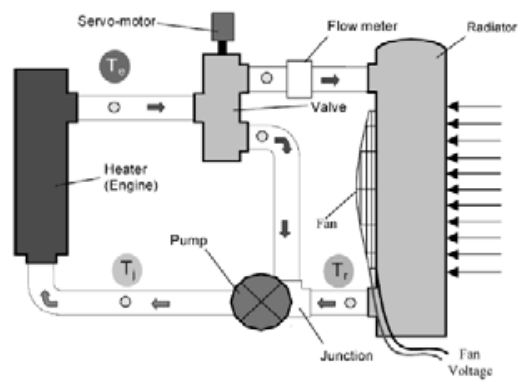

FIGURE II. SIMPLIFIED AUTOMOTIVE HEAT DISSIPATION SYSTEM

Salah [49] designed a nonlinear controller for the intelligent cooling system (the cooling system consists of a hydraulic driven pump and a hydraulic drive fan). A backsteppingrobust-control strategy adapted to the advanced cooling system is proposed. The controller can achieve a rapid and accurate tracking of temperature curves (3\%) and keep the temperature of the setting point. At the same time, it can minimize power loss, reduce parasitic loss and improve the thermal efficiency of diesel engine.

Borg Warner Corporation [50] proposed the dual mode cooling pump (DMCP) control strategy, as show in figure III.

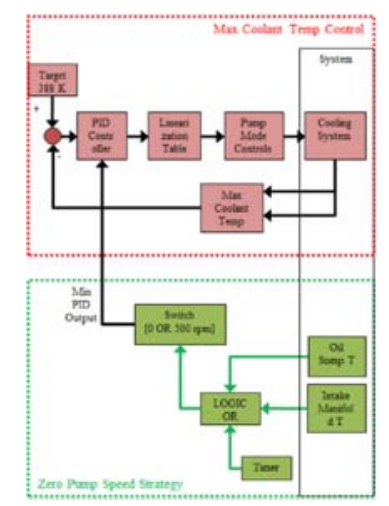

\section{FIGURE III. CONTROL STRATEGY OF DUAL MODE COOLANT WATER PUMP}

It combined with the common advantages of the mechanical pump and the electronic control pump. The pump algorithm is based on the control cooling liquid temperature and the pump speed. By observing the maximum electric speed of the pump and the pump efficiency, the selection of the mechanical pump module and the electronic control pump module is determined. In cold start, the "zero pump speed" control strategy is adopted, that is, during the warm or cold start process, the pump does not rotate or operates at a small speed of $500 \mathrm{r} / \mathrm{min}$, so as to ensure rapid warming up. The UDDS cycle test shows that the auxiliary power is reduced by $63.2 \%$, the friction loss is reduced by $10 \%$, and the fuel consumption is reduced by $2.15 \%$ after the application of the dual mode cooling water pump.

\section{INFLUENCE OF ENVIRONMENTAL BOUNDARY} CONDITIONS ON HEAT TRANSFER CHARACTERISTICS OF DIESEL ENGINE

With the change of the surrounding environment (atmospheric pressure, air density and ambient temperature), the physical and chemical properties of the coolant, the cooling capacity of the cooling air and other boundary conditions changed, resulting in the reduction of the environmental adaptability of the cooling system, and the environmental adaptability of the cooling system under the plateau environment was the most prominent. On the one hand, as shown in Table II [51], it can be seen that the boiling point of the coolant decreases obviously with the elevation. On the other hand, the air density decreases with the elevation, the Reynolds number decreases, the heat transfer coefficient between the environment and the radiator is changed, and the mass flow of the cooling fan is reduced, although the headfacing wind will be on the radiator during the vehicle driving process. The heat dissipation of the radiator has a certain gain effect, but at the same fan speed, the minimum heat dissipation ability of the radiator is reduced, and the diesel engine is easy to boil. In the world, there are many vehicles requiring high altitude operation. For China, there are more than 6 million of the existing plateau registered vehicles, most of which use diesel engine as power [52]. Therefore, it is of certain practical significance to study the influence of the plateau environment boundary conditions on the heat transfer characteristics of the cooling system.

TABLE II. CHANGES IN ATMOSPHERIC PARAMETERS AT DIFFERENT ALTITUDES

\begin{tabular}{|c|c|c|c|c|c|c|}
\hline Parameters & \multicolumn{6}{|c|}{ Numerical Values } \\
\hline Altitude $(\mathrm{km})$ & 0 & 1 & 2 & 3 & 4 & 5 \\
\hline Ambient pressure $(\mathrm{kPa})$ & 101.33 & 89.87 & 79.49 & 70.10 & 61.63 & 54.00 \\
\hline Air density $(\mathrm{kg} / \mathrm{m} 3)$ & 1.226 & 1.112 & 1.006 & 0.909 & 0.819 & 0.736 \\
\hline Ambient temperature $\left({ }^{\circ} \mathrm{C}\right)$ & 15 & 8.5 & 2 & -4.5 & -11 & -17.5 \\
\hline Boiling point $\left({ }^{\circ} \mathrm{C}\right)$ & 100.0 & 97.5 & 95.5 & 90.5 & 87.0 & 84.0 \\
\hline
\end{tabular}

In order to reduce the boiling point of the coolant in the plateau environment, the relevant measures are taken to install the expansion tank in the cooling system of the diesel engine, and the pressure cover is installed above the expansion tank to ensure that the cooling liquid is sealed with the external environment in the whole cooling cycle, so that the boiling point of the coolant will not be obviously reduced by the elevation of the altitude. 
For the change of heat dissipation boundary condition of radiator at high altitudes, the heat transfer characteristics of the cooling system under the plateau environment is researched by scholars. By means of intelligent control of cooling system, the thermal balance performance of plateau diesel engine caused by the change of boundary conditions was studied. But so far, the cooling system has not been accurately cooled for the change of boundary conditions.

The performance test of cooling system performance of 695Q naturally aspirated diesel engine and 695QZ turbocharged diesel engine at different altitudes was carried out in literature [53]. It was pointed out that the decrease of Reynolds number and the decrease of boiling point caused the decrease of heat dissipation capacity at high altitude. Meanwhile, the relative heat load of the cooling system was added with the elevation of the altitude, but the performance of the cooling system was on the plateau. The mechanism of environmental impact has not been studied in depth. Literature [54] studied the regularity of heat distribution with the altitude of the 6V150 turbocharged and medium cooled diesel engine. It was found that the heat of cooling water was less than $3000 \mathrm{~m}$ at the altitude of $3000 \mathrm{~m}$ at the altitude of $3000 \mathrm{~m}$, and it began to appear slightly downward trend, but at $4500 \mathrm{~m}$, the maximum cooling water cooling was dissipated by the decrease of power. The amount increased by $15 \%$. The Ge Yunshan team carried out field tests on the thermal efficiency of diesel engines at different altitudes $(0 \mathrm{~m}, 1600 \mathrm{~m}, 3300 \mathrm{~m}, 4500 \mathrm{~m})$ under low and medium load conditions. The results show that the thermal efficiency of the diesel engine decreases with the elevation, and it is particularly evident at low speed and small load conditions. It is considered that the combustion lag, the expansion ratio decrease, the air fuel ratio decreases, the efficiency of the turbocharger decreases, the fuel spray is deteriorated at low speed, and the heat load of the diesel engine increases as the diesel engine increases the external heat radiation. Enhanced heat dissipation leads to the deterioration of effective thermal efficiency in high altitude areas.

Zhang [55] revised the heat transfer coefficient of combustion chamber in different altitude according to the results of plateau simulation test of single cylinder engine, which based on the classical woschni heat transfer model. The corrected heat transfer model is applied to the simulation calculation at different elevations at various rotational speeds, and the error of the main working parameters is less than $10 \%$ after comparing with the test structure. Wang [56] corrected the heat transfer coefficient of the air side of the radiator at different altitudes and used the revised model to simulate the FLOW-MASTER software. Compared with the experimental results, the inlet and outlet water temperature errors of the radiators at $1000 \mathrm{~m}$ and $4500 \mathrm{~m}$ were less than $5 \%$.

\section{CONCLUSION}

This paper presented an inclusive review on the cooling and heat transfer of diesel engine. A vast number of available references showed that nanofluid technology, LHR engine technology, intelligent cooling system technology and the optimization of environmental boundary conditions can have a positive impact on the heat transfer characteristics of diesel engine. The heat dissipation is reduced and the thermal efficiency is improved after using these technologies. But for the current research, there are still some problems as follows:

- The optimal nanoparticle content in different nanofluids under different environments and engine configurations is uncertain.

- Due to the high temperature in the combustion chamber of LHR engine, there is a problem of ceramic layer peeling. Different types of LHR engine durability tests should be carried out.

- The efficiency of engine cooling system directly affects the heat load of heated components and engine thermal efficiency. The two-stage regulated turbocharged diesel engine is the main type to be used in plateau area in the future. Therefore, it is necessary to modify the heat transfer coefficient of the combustion chamber and the radiator of the high altitude two grade turbocharged diesel engine, and to explore the optimal control parameters of the cooling medium, so as to realize the intelligent integrated control of the diesel engine cooling system, which is the direction of the research on the cooling and heat transfer of the plateau diesel engine in the future.

\section{ACKNOWLEDGMENT}

This paper was supported by Machinery Industry Key Laboratory of Engine Plateau Adaptation.

\section{REFERENCES}

[1] Yang Shiming. Heat transfer[M]. Beijing: Higher education press, 1998.

[2] Yang Chunhao, Liu Ruilin, Chen Luyang, Zhang Zhongjie and Jiao Yufei. Research progress and prospect on thermal balance of vehicle engine[J]. Equipment environmental engineering, 2017(10): 63-68.

[3] Liao Ridong, Zuo Zhengxing and Zou Wensheng. The effect of temperature field on stress distribution of cylinder head[J]. Transactions of csice . 2001 , 19(3 ) : 253-257.

[4] Liu Zhien, Chen Guohua, Yang Wanli and Ye Xiaoming. The temperature field of CUB100 gasoline engine head[J] Design \& manufacture of diesel engine. 2003, 15 ( 1 ) : 10-13.

[5] YU Qihui, CAI Maolin, SHI Yan and Xu Qiyue. Optimization Study on a Single- cylinder Compressed Air Engine . Chinese Journal of Mechanical Engineering . 2015,11 (06) : 231-239.

[6] M. H. Shojaefard, M. R. Ghaffarpour, A. R. Noorpoor and S. Alizadehnia. Thermomechanical Analysis of an Engine Cylinder Head . Proceedings of the Institution of Mechanical Engineers[J], Part D: Journal of Automobile Engineering , 2006 , 220(5 ) :627-636.

[7] Z. K. Memon, T. Sundararajan and V. Lakshminarasimhan. Simulation and Experimental Evaluation of Air Cooling for Motorcycle Engine. Development ,2008, $01: 28-36$.

[8] Huang Chengfu .Investigation of thermo-mechanical coupling on cylinder head and block of diesel engine[D]. Wuhan: Huazhong university of science \& technology, 2012 , 1 6-29.

[9] Wang yu , Bai minli and Lv jizu .Analysis for thermo-mechanical strength of the cylinder head of 6110 diesel engine using whole component coupled method[J] Chinese internal combustion engine engineering. 2007, 6(28): 41-44

[10] W. Bryzik and R. Kaushasrimo. TACOM/Cummins adiabatic engine program. SAE Paper830314, 1983.

[11] R. Prasad and N. K. Samria. Heat transfer and stress fields in the inlet and exhaust valves of a semi-adiabatic diesel engine.Comput Struct 1990,34(5):765-77. 
[12] Yao Zhongpeng. Vehicle cooling heat transfer[M]. Beijing: Beijing Institute of Technology Press, 2001: 17-18.

[13] R. Kamo and W. Bryzik. Adiabatic turbocompound engine performance prediction.SAE Paper 780068, 1978.

[14] R. Kamo and W. Bryzik. Ceramics in heat engines. SAE Paper 790645 , 1979.

[15] R. Kamo and W. Bryzik. Cummins-TRADOCOM adiabatic turbocompounded engine program. SAE Paper 810070, 1981.

[16] R. Kamo and W. Bryzik. Cummins/TACOM advanced adiabatic engine. SAE Paper 840428, 1984.

[17] R.R. Sekar and R. Kamo. Advanced adiabatic diesel engine for passenger cars. SAE Paper 840434, 1984.

[18] I. Taymazi. An experimental study of energy balance in low heat rejection diesel engine[J]. Energy, 2006, 31(2-3): 364-371.

[19] M. V. S. M. Krishna, T. O. Prakash, P. Ushasri, N. Janardhan and P. V. K. Murthy. Experimental investigations on direct injection diesel engine with ceramic coated combustion chamber with carbureted alcohols and crude jatropha oil.[J]. Renewable \& Sustainable Energy Reviews, 2016, 53: 606-628.

[20] Li Chuang , Zhang yi , Hu dingyun, Cai Qiang, Zou Run and Ma Weikai. Effects of thermal barrier ceramic coating materials on diesel engine piston[J].Surface technology, 2017(02): 149-153.

[21] P. Olmeda, J. Martin, R. Novella and R Carreño. An adapted heat transfer model for engines with tumble motion[J]. Applied Energy, 2015, 158: 190-202.

[22] S. Broekaert, T. D. Cuyper, M. D. Paepe and S. Verhelst. Experimental investigation of the effect of engine settings on the wall heat flux during HCCI combustion[J]. Energy, 2016, 116: 1077-1086.

[23] S. Broekaert, J. Demuynck, T. D. Cuyper, M. D. Paepe and S. Verhelst. Heat transfer in premixed spark ignition engines part I: Identification of the factors influencing heat transfer[J]. Energy, 2016, 116: 380-391.

[24] T. D. Cuyper, J. Demuynck, S. Broekaert, M. D. Paepe and S. Verhelst. Heat transfer in premixed spark ignition engines part II: Systematic analysis of the heat transfer phenomena[J]. Energy, 2016, 116: 851-860.

[25] C. Choi, H. S. Yoo and J. M. Oh. Preparation and heat transfer properties of nanoparticle-in-transformer oil dispersions as advanced energy-efficient coolants [J]. Current Applied Physics, 2008, 8(6): 710712

[26] K. Y. Leong, R. Saidur, S. N. Kazi and A. H. Mamun. Performance investigation of an automotive car radiator operated with nanofluidbased coolants(nanofluid as a coolant in a radiator)[J]. Applied Thermal Engineering, 2010, 30(17/18): 2685-2692.

[27] Zhong xun , Yu Xiaoli, Zhang Yu and Liu Xiaojun. Design of heat transfer experiment for nanofluid in diesel oil cooler[J]. Transactions of csice, 2011(01): 67-71.

[28] Cui Wenzheng, Bai Minli, Lv Jizu and Li Xiaojie. Basic research on enhancing mechanisms of heat conduction of nanofluids for its application in cooling water jacket of IC engine[J]. Transactions of csice. 2013(06): 557-563.

[29] T. Castiglione, F. Pizzonia, R. Piccione and S. Bova. Detecting the onset of nucleate boiling in internal combustion engines[J]. Applied Energy, 2016, 164: 332-340.

[30] K. Kim, K. Choi, Y. Kim, K. Lee and K. Lee. Feasibility study on a novel cooling technique using a phase change material in an automotive engine[J]. Energy, 2010, 35(1): 478-484.

[31] Xu Deyang. Boiling heat transfer research on bridge zone in water jacket of gasoline engine cylinder head[D]. Jilin: Jilin University, 2016.

[32] Liu Xiaori , Li Ming zheng Qingping, Li Su and Li Guoxiang. Fluidsoild interaction heat transfer analysis of cylinder head in consideration of boiling and in-cylinder local heat transfer[J]. Chinese Internal Combustion Engine Engineering, 2017(06): 139-144.

[33] Hua Shiyang. Research on Experimental and Numerical Model of Supercooled Boiling Heat Transfer in Engine Cylinder Head [D]. Wu Han : Huazhong University of Science and Technology, 2016.

[34] N. A. F. Campbell, D. G. Tilley, S. A. Macgregor and L. Wong. Incorporating Nucleate Boiling in a Precision Cooling Strategy for Combustion Engines. SAE International Paper, 1997.
[35] S. G. Kandlikar and M. Bulut. An Experimental Investigation on Flow Boiling of Ethylene-Glycol/Water Mixtures. Journal of Heat Transfer, 2003, 125(2): 317-325.

[36] H. S. Lee, Heat transfer predictions using the Chen correlation on subcooled flow boiling in a standard IC engine. SAE International Paper, 2009.

[37] Gu Fang , Wu Huajie and Cui Guoqi. Subcooled boiling model based on VOF two-phase flow method and experimental verification on cylinder head[J]. Transactions of csice. 2014(04): 372-376.

[38] H. Kang, H. Ahn and K. Min. Smart cooling system of the double loop coolant structure with engine thermal management modeling[J]. Applied Thermal Engineering, 2015, 79: 124-131.

[39] D. Chalet, M. Lesage, M. Cormerais and T. Marimbordes. Noda modelling for advanced thermal-management of internal combustion engine[J]. Applied Energy, 2017, 190: 99-113.

[40] J. Feuerstein . Electronically Controlled Hydrostatic Fan Drive System for the Internal Combustion Engine [JJ. SAE Paper, 901586

[41] M. H. Salah, P. M. Frick, J. R. Wagner and D. M. Dawson. Hydraulic actuated automotive cooling systems-Nonlinear control and test[J]. Control Engineering Practice. 2009(17): 609-621.

[42] T. Hamamoto, S. Omura, N. Ishikawa and T. Sugiyama. Development of the electronically controlled hydraulic cooling fan system[J]. SAE Technical Paper Series,1990:1-8.

[43] Su yi. Engineering graduate thesis research on intelligent controlling technology of vehicle engine cooling system[D]. Nan jing: Nan jing university of science \& technology, 2006.

[44] P. Frick, H. Bassily, H. Watson and J. Wagner. A hydraulic fan driven heat exchanger for automotive cooling systems[J]. ASME, Dynamic System s and Control Division DSC, 2006.

[45] H. Cho, D. Jung, Z. S. Filipi, D. N. Assanis and J. Vanderslice. Application of Controllable Electric Coolant Pump for Fuel Economy And Cooling Performance Improvement[C]. IMECE 2004-61056.

[46] T. Mitchell, M. Salah, J. Wagner and D. Dawson. Automotive thermostat valve Configurations: enhanced warm-up performance[J]. Journal of Dynamic Systems Measurement and Control-Transactions of the ASME, 2009, 131( 4) : 044501.

[47] Li Chunming. APF type electronically controlled engine cooling system[J] Design, Calculation, Research, 2004( 11): 13-15.

[48] P. Setlur, J. R. Wagner. D. M. Dawson and E. Marotta. An advanced engine thermal management system: nonlinear control and test[J]. IEEE/ASME Transactions on Mechatronics, 2005, 10(2): 210-220.

[49] M. H. Salah, T. H. Mitchell, J. R. Wagner and D. M. Dawson. Nonlinear control strategies for advanced vehicle thermal management systems[J]. Transactions on Vehicular Technology, 2007, 57(1): 127-137.

[50] V. Negandhi, D. Jung and J. Shutty. Active Thermal Management with a Dual Mode Coolant Pump[J]. SAE International Journal of Passenger Cars-Mechanical Systems-Electronic Version, 2013, 6(2): 817-825.

[51] LIU Ruilin. Research on Plateau Environment Adaptability of Diesel Engine [M]. Beijing: Beijing Institute of Technology Press, 2013: 1-6.

[52] X. Wang, Y. S. Ge, L. Yu and X. Feng. Effects of altitude on the thermal efficiency of a heavy-duty diesel engine[J]. Energy, 2013, 59: 543-548.

[53] Dong Surong, Xu Xiang, Ren Xiaojiang, Guan Lizhe, Zheng Zhi, Liu Ruilin. Experimental study on high altitude (low air pressure) thermal equilibrium of naturally aspirated diesel engine[J]. Thermal science and technology.2011, 10(4): 365-370.

[54] Xu Xiang, Liu Ruili , Liu Gang, Ren Xiaojiang and Zhou Ping. A research on the effects of atmospheric pressure on the thermal balance of cooling system in diesel engine[J]. Automotive Engineering.2012,34 (7):592-595.

[55] Zhang Bowen. research on heat transfer in-cylinder model of diesel engine suitable for variable altitude. [D]. Zhejiang University, 2017.

[56] Wang Mao-hai , Chen Tao , Zhang Yang-jun. A research on the performance analyses of engine thermal management system at plateau[J]. Automotive Engineering, 2010, 32(10): 851-853+864. 